\title{
La pandemia por COVID-19: impacto en la ciencia y la tecnología
}

\section{The pandemic by COVID-19: impact on science and technology}

\author{
José M. Conde-Mercado*
}

Exdirección médica, Hospital Juárez de México, Ciudad de México, México

\begin{abstract}
Resumen
La reciente pandemia por enfermedad por coronavirus 2019 ha resultado en una afectación global en muchos aspectos de la vida humana. El artículo revisa dos aspectos del impacto de esta contingencia en salud en la ciencia, en particular la medicina y la tecnología. Se comentan las acciones de las agencias internacionales durante la pandemia en favor del conocimiento y desarrollo científico, el papel de la investigación online, las publicaciones médicas producidas en la pandemia y el impacto del confinamiento en la salud mental y cómo afrontarlo. En cuanto a la tecnología, se refiere cómo se adaptaron las empresas en nuevos dominios, la tecnología de los teléfonos celulares y su uso en la pandemia, la desinformación que se generó y como ocasionó fatiga de redes sociales; la aplicación de la inteligencia artificial y de las tecnologías de la industria 4.0 en apoyo a nuevas necesidades materiales, reducción de riesgos y capacitación, finalizando con un ejemplo de la teleoncología para apoyar a pacientes con cáncer en la contingencia.
\end{abstract}

Palabras clave: Pandemia. Ciencia. Tecnología. Impacto.

\section{Abstract}

The recent coronavirus disease 2019 pandemic has resulted in global impact in many aspects of human life. The article reviews two aspects of the impact of this contingency on health on Science, in particular Medicine and Technology. The actions of international agencies during the pandemic for scientific knowledge and development, the role of online research, the medical publications produced in the pandemic and the impact of confinement on mental health and how to deal with it are discussed. As far as technology is concerned, how companies adapted in new domains, cell phone technology and their use in the pandemic, the misinformation that was generated and how social media fatigue caused; the application of artificial intelligence and industry 4.0 technologies in support of new material needs, risk reduction and training, ending with an example of teleoncology to support patients with cancer in contingency.

Key words: Pandemic. Science. Technology. Impact.

\section{Introducción}

En el mes de diciembre de 2019 dio inicio la propagación de un virus denominado coronavirus 2 del síndrome respiratorio agudo grave (SARS-CoV-2), de la familia de los coronavirus, que produce una infección con una gama de presentaciones clínicas, siendo la más grave la neumonía; para el mes de marzo de 2020 la enfermedad por coronavirus 2019 (COVID-19) había sido declarada pandemia, con consecuencias fatales
Correspondencia:

*José M. Conde-Mercado

E-mail: jmcondem@yahoo.com.mx
Disponible en internet: 13-11-2020 Rev Hosp Jua Mex. 2020;87(3):149-158

www.revistahospitaljuarez.com 1405-9622/๑ 2020 Sociedad Médico-Quirúrgica del Hospital Juárez de México, A.C. Publicado por Permanyer. Este es un artículo open access bajo la licencia CC BY-NC-ND (http://creativecommons.org/licenses/by-nc-nd/4.0/). 
por la afectación a nivel mundial hasta mediados del mes de agosto de 2020 de más de 21 millones de pacientes, con una mortalidad de 765,820 personas. Es obvio que por ser una enfermedad nueva no tiene tratamiento aprobado, ni vacuna específica.

Muchos individuos han padecido además del distanciamiento social, el aislamiento y distanciamiento de sus amigos y familiares, otros problemas que van desde los más severos como la pérdida de empleos hasta otros de rangos menores como la necesidad de sacrificar parte de su presupuesto con el fin de pagar el Internet que sus hijos necesitan para seguir estudiando en casa. Los investigadores también se han visto afectados con el cierre de los laboratorios y la necesidad de trabajar en casa, lo cual para la investigación no es tarea sencilla.

Por un lado, evidentemente se ha producido una reducción de la productividad en un gran número de campos de la ciencia y en programas institucionales, aunque por otro lado se han abierto oportunidades de financiamiento de varias agencias gubernamentales para la investigación del reto que representa esta enfermedad, con el objetivo de poder ofertar a la sociedad opciones terapéuticas efectivas, así como desarrollar el mecanismo de inmunidadmásadecuado comoson las vacunas, parafinalmente en un futuro próximo controlar esta pandemia.

Los impactos en muchas esferas que ha tenido la pandemia han sido significativos y en el presente artículo el objetivo es mostrar cómo ha impactado en la ciencia, sobre todo en la medicina y la tecnología.

\section{Impacto en la ciencia y la medicina}

Siendo la medicina una rama importante de la ciencia moderna, en esta publicación presentaremos en forma combinada los varios efectos que ha tenido la pandemia por la enfermedad causada por el SAR-CoV-2 en ambas disciplinas.

\section{Acciones de organismos internacionales en favor de la ciencia y medicina}

La Organización Mundial de la Salud (OMS) en mayo del presente año, organizó un teletón para recabar un total de 8 billones de dólares procedentes de 40 países para soportar el rápido desarrollo de vacunas para prevenir la COVID-19, además de anunciar el despliegue del estudio internacional denominado SOLIDARIDAD, que es multicéntrico y coordinado por la organización, para evaluar simultáneamente varios candidatos para la vacuna que se encuentran en fase clínica II-III y el estudio de tratamientos de la enfermedad en fases II-IV que compara cuatro tratamientos para pacientes hospitalizados con COVID-19 severa, estudio que ha asociado más de 100 países y sus científicos, que han unido sus infraestructuras de laboratorios y sobre todo sus conocimientos y experiencias para estudiar los beneficios, así como los riesgos, utilidad y seguridad de las vacunas potenciales y los fármacos más prometedores para controlar la enfermedad'1. Por otro lado, la Coalición para las Innovaciones en Preparación de Epidemias denominada CEPI (por sus siglas en inglés) ha organizado un fondo mundial de 2,000 millones de dólares para la inversión rápida y el desarrollo de candidatos a vacunas, la cual podría estar disponible en los primeros meses de 2021.

El Laboratorio Nacional Lawrence Livermore, un centro de desarrollo e investigación financiado con fondos federales de los EE.UU. y fundado por la Universidad de California en 1952, recibió la indicación de la Fuerza de Tarea de la Casa Blanca sobre COVID-19 de utilizar la mayor parte de su capacidad de supercomputación para una investigación a gran escala del flujo del virus, sus posibles mutaciones y otros aspectos de la enfermedad a costa de reducir o suspender otros proyectos ${ }^{2}$.

El Laboratorio de Biología Molecular Europeo cerró sus instalaciones en seis ciudades del continente, pero puso a disposición de los gobiernos de los países donde se ubican al personal de investigadores para colaborar en la investigación de la pandemia, muchos de ellos manteniendo el aislamiento social y el teletrabajo. Por otro lado, en abril, la Comisión Europea por medio del Laboratorio Europeo de Bioinformática creó la Plataforma de Datos COVID-19, cuyo fin es estructurar un entorno europeo y global abierto, confiable y escalable donde los investigadores puedan almacenar, recabar y compartir conjuntos de datos como secuencias de ADN, estructuras de proteínas del virus, datos de investigaciones clínicas y epidemiológicas, el cual está constituido por dos componentes importantes: la base de datos SARS-CoV-2 y un portal abierto, acciones que acentúan el compromiso de la Comisión con la Ciencia Abierta ${ }^{3}$.

En marzo del presente año, el Departamento de Energíade los EE.UU., laFundación Nacional paralaCiencia ylaNASA, asociados conlaindustriaynueveuniversidades, reunieron sus recursos para poder accederalas supercomputadoras de IBM, además de la «nube» de HewlettPackard, Amazon, Microsoft y Google para estudiar fármacos potenciales como tratamiento de la COVID-19. Este organismo, denominado Consorcio de Computo de 
Alto Rendimiento para la COVID-19, se dedica al desarrollo de posibles vacunas y escrudiña miles de compuestos para la terapéutica.

El Instituto de Transformación Digital C3.ai es una corporación de investigación dedicada a acelerar los beneficios de la inteligencia artificial para las empresas, el gobierno y la sociedad de losEE.UU. En un ejemplo más de colaboración en favor de la ciencia durante esta pandemia, unió sus fortalezas con cinco universidades, el Instituto de Tecnología de Massachusetts y el Centro Nacional de Aplicaciones de Supercomputadoras en Illinois, para que, con una compañía privada fundada por Thomas Siebel, ubicaratodos los recursos de supercómputo para descubrir nuevos fármacos, desarrollar protocolos terapéuticos y estrategias de salud pública, con el compromiso de patrocinios que atraigan investigadores de todo el mundo para realizar estas tareas.

En el mes de marzo el proyecto Folding@home lanzó un programa de asistencia a todos los investigadores a nivel mundial con el objetivo de estudiar mediante computación distribuida y simulación avanzada las potenciales proteínas diana del SARS-CoV-2 y del resto del virus para el desarrollo de fármacos y obviamente de la vacuna.

Durante el mes de mayo, el Instituto de Investigaciones Scripps y la Comunidad de IBM presentaron un proyecto conjunto denominado Open-Pandemics-COVID-19 para predecir la efectividad de medicamentos candidatos al tratamiento de la enfermedad $y$, dado que se requieren millones de simulaciones, se ha diseñado para poder trabajar con computadoras personales de voluntarios en los hogares, aprovechando el aislamiento social, lo cual es un acercamiento de los científicos con miembros de la sociedad en búsqueda de soluciones a la amenaza que es la COVID-19.

Otros recursos que implican la denominada ciencia computacional se encuentran en funcionamiento mediante proyectos de investigación acerca de la COVID-19. Se pueden enumerar de la siguiente manera:

-Proyecto Abierto Eterna para la vacuna, que impulsa

a jugadores de videojuegos para «diseñar un código de mRNA para la vacuna potencial contra el nuevo virus».

- El proyecto EU-Citizen Science, que recaba recursos por medio de la informática relacionados con la pandemia.

- El proyecto COVID-19-Citizen Science, como una iniciativa nueva de la Universidad de San Francisco en conjunto con sus médicos e investigadores para guiar a científicos jóvenes y ciudadanos interesados en mejorar el entendimiento de la enfermedad.

- Un plan denominado CoronaReport, que mediante periodismo digital «democratice» los reportes sobre los coronavirus, haciéndolos accesibles a los ciudadanos legos en la materia médica.

- Un proyecto denominado Rastreador de síntomas de COVID-19 para uso de las personas que tienen duda sobre si pueden padecer la enfermedad, que es accesible mediante Internet y que hasta el mes de abril había tenido más de dos millones de descargas.

\section{Investigación online}

El hecho de realizar investigaciones en línea, cuando el tema que indagan lo permite, ofrece ciertos beneficios: es rápida, eficiente y más barata. Un grupo de científicos e investigadores que estudian los aspectos cognitivos durante la pandemia ha tenido hallazgos muy interesantes e insospechados. Uno de estos es la mayor participación en la investigación científica de aspectos psicológicos, como los realizados por la Colaboración Padres-Investigadores de childrenshelpingscience.com, una plataforma donde investigadores de varios laboratorios invitan a familias a participar en sus estudios, los cuales esencialmente van dirigidos a conocer con mayor profundidad diversos fenómenos como la proeficiencia de lenguaje, el razonamiento espacial y el desarrollo cerebral. Una de las recomendaciones surgidas de la experiencia con las investigaciones durante la pandemia es que la adquisición de datos útiles en la investigación realizados en línea deberá estar complementada por información demográfica de los participantes. Uno de los principales obstáculos para obtener información en línea aun en países como los EE.UU. es la falta de disponibilidad de Internet por parte de las familias y se ha detectado que $>21$ millones de norteamericanos, sobre todo de origen hispano, no tiene acceso o este es muy limitado (menos de $25 \mathrm{Mb} / \mathrm{s}$ ). La manera como se ha solventado esta carencia ha sido mediante el uso del Internet en lugares públicos como bibliotecas, parques, etc., pero con la dificultad del desplazamiento de las personas por la cuarentena, otra forma más de solucionarlo ha partido de las Universidades como las de lowa, Illinois e Indiana mediante laboratorios móviles de cómputo o de compañías proveedoras de Internet que a pesar de la crisis económica han disminuido sus tarifas para uso de esta tecnología e incluso lo han proporcionado gratuitamente cuando conocen que está ligado a trabajos de investigación ${ }^{4}$. 


\section{Investigadores jóvenes en tiempos de COVID-19}

No solo los investigadores de planta ubicados en los grandes centros de investigación o en las universidades han sufrido detrimento en su actividades habituales, al tener que cerrar total o parcialmente estos 0 disminuir el trabajo en sus laboratorios, dejar de asistir a conferencias y congresos y probablemente la amenaza de ver mermados sus patrocinios para estudios de investigación; también los investigadores noveles han experimentado estos impactos y sin embargo su entereza, voluntad y juventud han hecho que sigan adelante. Esto se ve reflejado en las afirmaciones que hacen varios de ellos a nivel mundial en la revista Cell Stem Cell donde declaran, por ejemplo: Katie Galloway del Instituto Tecnológico de Massachussets que sigue trabajando con limitaciones en el conocimiento de circuitos genéticos sintéticos que en el futuro sean capaces de mejorar la regeneración de tejidos; Ying Xi de la Universidad Tecnológica de Shanghái, quien en su laboratorio de biología pulmonar estudia las respuestas del epitelio del pulmón ante agentes destructores de este, como es el caso de la COVID-19; las poblaciones de células progenitoras que median la homeostasis pulmonar y la reparación tisular pulmonar; Harry Leitch del Instituto de Ciencias Médicas MRC de Londres que en su laboratorio trabaja con células multipotenciales y su aplicación en el estudio de infertilidad y de los tumores germinales en niños, así como muchos otros jóvenes investigadores que coinciden en manifestar que han tenido que modificar sus actividades y la forma de comunicarse e interactuar con otros científicos del mundo para poder continuar con la investigación, sin que esta se detenga y así han enfrentado el reto de continuar impulsando la ciencia en estos momentos difíciles para la humanidad ${ }^{5}$.

Al mes de iniciada la pandemia, en una encuesta de 4,500 científicos se notó que las mujeres habían disminuido su productividad debido al menor tiempo del que disponían para las labores de indagación científica, por tener que realizar funciones familiares en el confinamiento, con una mayor frecuencia de interrupciones, en especial aquellas que tienen hijos pequeños y como refiere Crystal D. Rogers, de la Universidad de California: «reconozco la necesidad de continuar con publicaciones, intercambios con otros científicos y otras obligaciones en el laboratorio, pero ¿cómo se puede mantener la excelencia mientras se trata de equilibrarla con un nuevo tipo de vida?».
Francis Collins menciona que nunca había visto que la investigación se moviera tan rápidamente, sin embargo considera que la velocidad aún es «lenta» dado el gran reto de la urgencia por controlar la enfermedad que ha puesto en jaque nuevamente a la humanidad.

\section{Publicaciones médicas}

La forma tradicional de publicación de la investigación científica ha cambiado drásticamente durante el desarrollo de la pandemia, se ha mejorado la comunicación entre los científicos y se han establecido nuevas formas de hacerla. Muchos datos a una velocidad récord y en grandes cantidades se han ubicado en las plataformas de Internet en la forma de prepublicaciones, las cuales carecen de revisiones, lo cual demerita la calidad del contenido publicado, pero por otro lado se ha observado una inmensa comunicación entre científicos.

La necesidad de acelerar la investigación científica abierta hecha por varias organizaciones de la sociedad civil para crear un compromiso sobre recursos para COVID-19 impulsó la petición hecha a muchas industrias de ceder sus derechos de propiedad intelectual durante la pandemia para ayudar a encontrar la cura de la enfermedad. Esto tuvo efectos positivos e hizo que varios gigantes tecnológicos se unieran a este compromiso.

Organizaciones que por largo tiempo han impulsado el acceso abierto como Creative Commons implementaron una serie de acciones para promover la Ciencia Abierta como elemento clave con políticas específicas y claras, así como un llamado a los científicos para adoptar un periodo de cero embargo en las publicaciones, para que todo estudio realizado en relación a los coronavirus tuviera un abordaje a través de las páginas web incluyendo portales como el de la Universidad de Cambridge 0 de editoriales como Elsevier, que puso en disposición del cuerpo médico e investigadores una base de artículos de sus revistas, con un alcance a mediados de agosto de 2020 de más de 37,000 publicaciones gratuitas a texto completo.

La Dra. Nowakowska en Polonia realizó una búsqueda sistemática de artículos en inglés sobre COVID-19 publicados entre los meses de enero y marzo de 2020 y encontró 2,062 publicaciones en 578 revistas, el 78.6\% de ellas se habían publicado exclusivamente en marzo. Tres revistas médicas importantes abarcaban un porcentaje importante de las publicaciones: British Medical Journal, The Lancet y Journal of Medical Virology, 


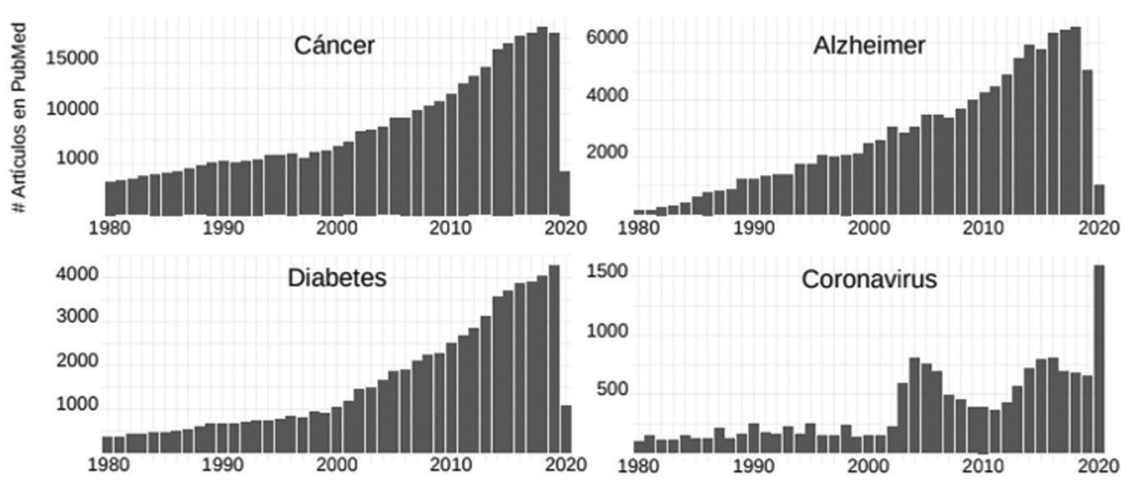

Figura 1. Artículos inscritos en la plataforma PubMed sobre temas de cáncer, Alzheimer, diabetes mellitus y coronavirus.

llamando la atención que solo el $21.3 \%$ de las publicaciones eran investigaciones originales y el $6.1 \%$ reportes de casos, y había solo 10 metaanálisis. Los temas referentes a estas investigaciones van desde la epidemiologia de la enfermedad hasta aspectos clínicos, el diagnóstico y la prevención. Los países que más habían publicado eran China, EE.UU., Reino Unido e Italia. Los investigadores de América Latina representados por Brasil y Colombia contribuyeron con 48 artículos y desafortunadamente México no publicó ni un solo trabajo. Si se compara la cantidad de publicaciones para esta enfermedad con los 5,563 artículos sobre el síndrome respiratorio del Medio Oriente que se publicaron en el lapso de 2012 a 2019, la cantidad en esta ocasión ha sido muy significativa. Nuevamente la colaboración de muchas instituciones que se dedican a la publicación de temas médicos a través del Wellcome Trust ha hecho posible la disponibilidad sin costo de las publicaciones para el público y los investigadores ${ }^{6}$.

La revista Nature y el Wellcome Trust lanzaron el Outbreak Science Rapid PREreview, una plataforma abierta para la revisión rápida de artículos preprints, lo cual es otro ejemplo de la subvención entre organizaciones que preocupadas por la pandemia han respondido sin escatimar esfuerzos y recursos para resolver esta amenaza. En la figura 1 se puede observar en forma comparativa las publicaciones en la plataforma PubMed relativas a cuatro enfermedades en donde se observa que en los primeros meses del año 2020 las referentes a coronavirus superan por mucho a las otras tres enfermedades.

Hagani, et al., de la Universidad de Sídney, realizaron un estudio de análisis bibliométrico profundo de las publicaciones sobre COVID-19, utilizando el término «coronavirus» con un enfoque hacia la seguridad.
Encontraron un total de 12,109 artículos y cuando ocuparon un filtro solo para coronavirus 2019 se redujo a 1,239 investigaciones; de ellas el $40 \%$ eran artículos originales y los restantes notas, editoriales, revisiones de tema y cartas al editor. De estas contribuciones a la divulgación científica el $30 \%$ provenían de China y el $14 \%$ de EE.UU., con un enfoque en tres ramas: microbiología médica, epidemiologia genética y ciencias biomédicas y se identificaron como aspectos de seguridad tres áreas sobre medicamentos, tratamiento y vacunas, así como 10 dimensiones de seguridad.

\section{Impacto en la salud mental}

La pandemia por COVID-19 ha sido una profunda amenaza a las motivaciones más básicas de los seres humanos, especialmente la conexión humana, y una de las consecuencias que va a dejar es la huella en la salud mental. De acuerdo con la hipótesis de Maslow sobre las necesidades básicas, la satisfacción de la conexión humana está relacionada con el amor y la pertenencia, y se considera a la conexión social como la más importante para sobrevivir entre los seres humanos. El aislamiento físico y la separación prolongada del ser humano, de su familia, amigos y compañeros de trabajo motivada por la pandemia es incompatible con los instintos y motivaciones humanas. De acuerdo con los estilos de biotipo cerebral, las afectaciones durante la pandemia originaran tres tipos de afectación:

- Rumiación, constructo muy cercano a la depresión, que origina preocupaciones internas intensas por el futuro, exacerba el sentido de vulnerabilidad hacia la enfermedad y la ansiedad por el estado de salud, afectando por tanto la satisfacción por la vida y la salud psicológica. 
- Anhedonia, con una falla relativa en experimentar placer con actividades o estímulos que normalmente lo originan; generalmente se comporta en forma de un círculo vicioso que hace que el distanciamiento social cause un grado importante de desmotivación para conectarse con otros, lo que también se relaciona a exacerbación de depresión, sentimiento de una mala calidad de vida e incluso de ideación suicida.

- Desregulación de amenazas, la cual también afecta las relaciones y conexiones con otros individuos, lo que favorece que los sujetos se aíslen, rechacen a los demás y muestren pensamientos negativos, lo que incrementa la desconexión social, originando una gran ansiedad y depresión.

- Como se ve, la afectación en la salud mental por COVID-19 no es importante solamente por el aislamiento, a lo que si además se agrega que el sujeto se haya enfermado o perdido algún familiar, las consecuencias serán aún mayores ${ }^{7}$.

Se presenta en la tabla 1 una relación de temas factibles que investigar durante el resto de la pandemia y posteriormente con la finalidad de mejorar la calidad de vida de los seres humanos, considerando desde aspectos en el trabajo, la nueva forma de vivir y otros aspectos importantes.

\section{Impacto de la pandemia por COVID-19 en la tecnología}

Otro de los impactos que ha tenido la actual pandemia ha sido sobre muchos aspectos tecnológicos y sus aplicaciones. Durante la pandemia, el uso de Internet a nivel mundial ha experimentado un aumento del 50 al $60 \%$ en la utilización de la banda ancha del Grupo BT y Vodafone; mientras tanto Netflix, Disney, Google, Amazon y YouTube consideraron reducir la calidad de sus vídeos para evitar esa sobrecarga y Sony comenzó a ralentizar las descargas de juegos de PlayStation en Europa y EE.UU. para mantener el nivel de tráfico ${ }^{8,9}$.

\section{Adaptaciones de algunas empresas a un nuevo dominio}

Por otro lado, también la tecnología buscó nuevas formas de producir bienes durante la pandemia, muchas grandes empresas transnacionales cambiaron su dominio, por el que han sido reconocidas, y han creado su «marca» por nuevas actividades útiles en la pandemia, lo que permitió que siguieran laborando,
Tabla 1. Oportunidades de investigación en proyectos para mejorar la vida de las personas

\begin{tabular}{|l|l|l|}
\hline \multicolumn{2}{|c|}{ Oportunidades de investigación en provectos para mejorar la } \\
vida de las personas
\end{tabular}

Adaptada de Ventatesh, $2020^{8}$

mantuvo los empleos de sus trabajadores, aprovechó la infraestructura y conocimientos de sus talentos humanos conocedores de la tecnología y sobre todo proporcionó insumos muy necesarios en estos momentos. Presentamos en la tabla 2 un listado de empresas que modificaron su producción y los nuevos rubros donde participaron ${ }^{10}$. 
Tabla 2. Industria de manufactura antes y durante la pandemia de COVID-19

\begin{tabular}{|l|l|l|l|}
\hline \multicolumn{3}{|c|}{ Industria de manufactura antes y durante la pandemia de } \\
COVID-19 \\
\hline Compañía & Dominio & Antes & Durante \\
\hline Ford & $\begin{array}{l}\text { Industria } \\
\text { automotriz }\end{array}$ & Vehículos & $\begin{array}{l}\text { Ventiladores } \\
\text { mecánicos }\end{array}$ \\
\hline Airbus & $\begin{array}{l}\text { Industria } \\
\text { aeroespacial }\end{array}$ & Aviones & $\begin{array}{l}\text { Ventiladores } \\
\text { mecánicos }\end{array}$ \\
\hline Mercedes & $\begin{array}{l}\text { Industria } \\
\text { automotriz }\end{array}$ & $\begin{array}{l}\text { Motores } \\
\text { para F-1 }\end{array}$ & Máquinas de CPAP \\
\hline Gucci & $\begin{array}{l}\text { Industria de } \\
\text { la moda }\end{array}$ & $\begin{array}{l}\text { Ropa de } \\
\text { lujo }\end{array}$ & Mascarillas \\
\hline Bacardí & $\begin{array}{l}\text { Bebidas } \\
\text { alcohólicas }\end{array}$ & Ron & $\begin{array}{l}\text { Sanitizantes de } \\
\text { manos }\end{array}$ \\
\hline Eigth Oaks & Destilería & Licores & Desinfectantes \\
\hline
\end{tabular}

CPAP: presión positiva continua de las vías respiratorias. Adaptada de Elavarasan, $2020^{\circ}$.

\section{Uso de la tecnología de los teléfonos celulares inteligentes en la pandemia}

La determinación de muchos gobiernos en países del mundo de confinar a sus ciudadanos durante parte de la duración de la pandemia para evitar contagios motivó una disminución del movimiento de las personas en las comunidades y para lograr la comunicación entre personas el uso de los llamados teléfonos inteligentes (SP, smartphone) se incrementó en parte para conocer noticias sobre la pandemia y conceptos de la enfermedad por SARS-CoV-2. En el campo de la medicina ha sido un importante impulsor de la telemedicina. Un SP es un teléfono celular al cual se le ha integrado tecnología de cómputo, un sistema operativo, posibilidad de «hojear» en la red y correr aplicaciones diversas de software; además poseen cámara, sistema de posicionamiento del usuario conocido como GPS y juegos. Con antelación a la pandemia, muchas de las especialidades médicas, entre ellas la ortopedia, ya ocupaban esta tecnología para apoyar no solo el diagnóstico especialmente de imágenes, sino también para valorar a distancia datos clínicos y de estudios de laboratorio de pacientes, hacer prescripciones o modificarlas y realizar seguimiento.

La denominada tecnología $5 \mathrm{G}$, que se caracteriza por mayor velocidad, movilidad, eficiencia energética y menor latencia, durante la pandemia ha sido de mucha utilidad en campos como el diagnóstico, en especial radiológico, donde algunas investigaciones previas habían demostrado por lo menos en situaciones como el diagnóstico de fracturas una especificidad del $97.7 \%$ y una sensibilidad del $94.4 \%$. Estas experiencias mediante la utilización de la aplicación llamada WhatsApp sirvieron durante esta situación anómala para el diagnóstico de imágenes de radiografías y tomografías pulmonares con mucho éxito y sin riesgo para los radiólogos. Otras aplicaciones que por medio de los SP se han utilizado en esta contingencia han sido: el triaje de pacientes con sospecha de la enfermedad, la planeación diagnóstica y sobre todo de tratamientos, así como el seguimiento de estos; también en la orientación a pacientes y familiares de posibles contagios. En algunos países se utilizó para proporcionar el consejo grupal mediante conexiones múltiples. Una experiencia hindú con la aplicación de los SP denominada Aarogya Setu (traducido como puente de salud) se ocupó para determinación de riesgo de casos sospechosos que habían tenido contacto con pacientes con COVID-19. El uso ha sido muy extendido y probablemente se verán consecuencias de afecciones médicas secundarias, no a la enfermedad por SARS-CoV-2 sino al abuso de esta tecnología, como son la tenosinovitis del codo, síndrome del túnel del carpo o de salida torácica entre otros ${ }^{11}$.

\section{Inteligencia artificial y conocimiento de aprendizaje automático}

Ambas tecnologías desde antes de la pandemia actual han sido utilizadas en el ámbito de la medicina para impulsar acciones diversas, no como una forma de desplazamiento hacia las máquinas de decisiones que deben seguir tomando los seres humanos, en este caso los médicos, sino como un auxiliar en el proceso, por ejemplo, de decisión diagnóstica o de tratamiento. Las dos tecnologías se usaron durante la pandemia para aumentar la efectividad de los procesos de diagnóstico y de escrutinio de casos, no solo en el caso de la clínica, también en la evaluación de estudios como la tomografía computarizada de tórax, con una herramienta auxiliar denominada Resnet-101, que demostró que usada por radiólogos con sobrecarga de trabajo logró una especificidad del $86.2 \%$ y una sensibilidad del $83.3 \%$ y fue especialmente útil en la predicción de hallazgos en enfermos críticos o graves, que muy probablemente hubieran escapado a los especialistas. En el caso del laboratorio, la utilización de un algoritmo denominado «bosques aleatorios» (que son 
una combinación de árboles predictores) detectó 11 índices relevantes en las pruebas de pacientes en China, con los cuales el diagnóstico fue mas certero y rápido, con una sensibilidad del $95.95 \%$ y una especificidad del $96.97 \%$.

La utilización de estas técnicas en 36 países, entre ellos México con una aplicación llamada CovidRadar, durante la contingencia, que emplearon para el rastreo de contactos por vía digital, además de que la aplicación de este y otros algoritmos, pudo significativamente mejorar el tratamiento, medicación, escrutinio, sondeoy el proceso de desarrollo de medicamentos nuevos o su reutilización y la vacuna ${ }^{12}$.

En particular para la reutilización de medicamentos, que se ha definido por la OMS como el uso de fármacos que se prescriben en otras enfermedades en forma habitual y que durante la pandemia se emplean como tratamientos emergentes, ya que comparativamente a la forma tradicional el desarrollar nuevos medicamentos puede ser un proceso que tarde entre 10 y 15 años, además de que es complejo, costoso y necesita grandes inversiones, lo cual obviamente no puede ser una estrategia lógica en el caso de una pandemia. Siete empresas de alta tecnología y expertas en el mecanismo de reutilización de fármacos, de países como Reino Unido, EE.UU., Corea, Alemania, India y Canadá trabajaron con medicamentos como la cloroquina y la hidroxicloroquina, el remdesivir, el tocilizumab, el baricitinib, el atazanavir y mezclas de dos o tres de ellos, así como otras 6,700 moléculas como método de lograr el control definitivo de la enfermedad de una manera no solo sintomática, sino definitiva por su efectos como antivirales 0 antiinflamatorios ${ }^{13}$.

\section{Desinformación compartida y fatiga de medios sociales}

Además de la pandemia existente y como consecuencia de la gran utilización de elementos de uso generalizado como los SP, también se padeció una «infodemia», la cual se caracterizó por la utilización tanto de Internet como de las diferentes redes sociales para difundir noticias falsas (fake news), notas no verificadas, así como mucha desinformación sobre aspectos de la enfermedad y particularmente de su evolución, con una consecuencia de lo que se ha denominado «fatiga de los medios sociales». Los resultados de una investigación realizada en Asia sobre las razones de la difusión de desinformación encontraron que se debe principalmente a una autopromoción en los medios o simplemente por diversión, especialmente entre los jóvenes usuarios, además de que se ha detectado la carencia de métodos efectivos de regulación en las plataformas. La información no verificada y generalmente difundida por terceros, las noticias sarcásticas de carácter político y las burlas, que en nuestro medio se conocen coloquialmente como «memes» son las más frecuentemente difundidas en forma por demás irresponsable ${ }^{14}$.

\section{Aplicaciones de las tecnologías de la industria 4.0 durante la pandemia}

La denominada industria 4.0 conforma la cuarta revolución industrial. Consiste en tecnologías de la información y de manufactura avanzada que cubren necesidades en diversas áreas de la vida de los seres humanos. Tiene máquinas soportadas por conectividad inalámbrica y sensores y se utiliza frecuentemente para el control de líneas de producción. Durante la pandemia al proporcionar una cadena inteligente de insumos médicos y equipos para ser utilizados de inmediato en la crisis sanitaria mediante el diseño de software que acelera y optimiza la producción de piezas de diversas características. La aplicación de las tecnologías de la industria 4.0 tiene ventajas como: proveer insumos médicos a tiempo mediante cadenas de suministro inteligentes, uso de robots autónomos para reducir riesgos de contagios en el personal de salud, al realizar labores peligrosas y dejar tiempo a estos para la atención de los pacientes, utilizar la realidad virtual para capacitación y entrenamiento, y participar en la evaluación de riesgos y de salud pública global durante la emergencia. En la tabla 3 se presentan las tecnologías significativas de la industria. 4.0 que han sido de utilidad durante la pandemia, con ejemplos ${ }^{15}$.

\section{Uso de la teleoncología durante la pandemia de COVID-19}

La necesidad de atención de un número cada vez más significativo de pacientes con COVID-19 hizo que muchos hospitales enviaran a sus casas a ciertos pacientes para mantenerlos aislados y evitar así que por sus condiciones de inmunodeficiencia por los tratamientos aplicados pudieran adquirir la enfermedad, lo que ocurrió sobre todo con los pacientes oncológicos en todo el mundo. Con el antecedente de haber utilizado tecnologías modernas de comunicación a distancia como audio y video, en lo que se conoce como telemedicina y que se ha aplicado previamente en especialidades como cardiología, medicina 
Tabla 3. Tecnologías significativas de la industria 4.0 útiles en la pandemia por COVID-19

\begin{tabular}{|c|c|c|}
\hline \multicolumn{3}{|c|}{ Tecnologías significativas de la industria 4.0 útiles en la pandemia por COVID-19 } \\
\hline Tecnología & Descripción de tecnología & Áreas de utilidad \\
\hline $\begin{array}{l}\text { Inteligencia } \\
\text { artificial }\end{array}$ & $\begin{array}{l}\text { Inteligencia llevada a cabo por máquinas, como las } \\
\text { computadoras, que maximiza la posibilidad de éxito en } \\
\text { algún objetivo o tarea especifica }\end{array}$ & $\begin{array}{l}\text { Vigilancia de la diseminación } \\
\text { Examen clínico de pacientes } \\
\text { Realización de estudios de imagen } \\
\text { Estudios clínicos de fármacos y vacunas } \\
\text { Desinfección de áreas } \\
\text { Producción de insumos médicos }\end{array}$ \\
\hline $\begin{array}{l}\text { Internet de } \\
\text { las cosas }\end{array}$ & $\begin{array}{l}\text { Solución automatizada con tremendo crecimiento que } \\
\text { colecta, transfiere, analiza y almacena datos, accesible } \\
\text { en diversos equipos }\end{array}$ & $\begin{array}{l}\text { Uso de drones: } \\
\text { Búsqueda del paciente "cero" } \\
\text { Seguimiento de contactos } \\
\text { Monitoreo de pacientes en domicilio } \\
\text { Vigilancia de rupturas del aislamiento social }\end{array}$ \\
\hline $\begin{array}{l}\text { Macrodatos } \\
\text { (Big data) }\end{array}$ & $\begin{array}{l}\text { Técnica analítica de una cantidad voluminosa de datos } \\
\text { estructurados, semiestructurados y no estructurados, } \\
\text { con el potencial de ser extraídos para obtener } \\
\text { información }\end{array}$ & $\begin{array}{l}\text { Colección de datos e información a nivel mundial en tiempo } \\
\text { real y actualizados en forma continua }\end{array}$ \\
\hline $\begin{array}{l}\text { Realidad } \\
\text { virtual }\end{array}$ & $\begin{array}{l}\text { Técnica digital que permite crear imágenes y espacios } \\
\text { simulados, mediante un dispositivo visual, que provee } \\
\text { una experiencia con la sensación de estar y } \\
\text { desenvolverse dentro de ellos }\end{array}$ & $\begin{array}{l}\text { Herramienta de comunicación, colaboración y planeación } \\
\text { de grupos } \\
\text { Capacitación y adiestramiento del personal de salud } \\
\text { Enfoque de tareas sin posibilidades de distracción }\end{array}$ \\
\hline Holografía & $\begin{array}{l}\text { Técnica fotográfica que permite obtener una imagen } \\
\text { con un efecto tridimensional, mediante el uso de un } \\
\text { rayo láser }\end{array}$ & $\begin{array}{l}\text { Realización de eventos en vivo y conferencias con la } \\
\text { posibilidad de asistencia virtual de miles de oyentes, en } \\
\text { especial cuando se utiliza el tipo de ultrarrealismo que } \\
\text { posee esta tecnología }\end{array}$ \\
\hline $\begin{array}{l}\text { Uso de la } \\
\text { «nube» }\end{array}$ & $\begin{array}{l}\text { Técnica que consiste en trasladar parte de los archivos } \\
\text { informáticos a un conjunto de servidores a los que se } \\
\text { puede acceder por medio de Internet }\end{array}$ & $\begin{array}{l}\text { Incremento de la posibilidad de almacenamiento de } \\
\text { información que en tiempo de pandemia se acrecienta en } \\
\text { particular para médicos e investigadores }\end{array}$ \\
\hline $\begin{array}{l}\text { Robots } \\
\text { autónomos }\end{array}$ & $\begin{array}{l}\text { Robot que puede operar con un alto grado de } \\
\text { autonomía, lo que es particularmente deseable en } \\
\text { campos o tareas que, por ser pesadas o riesgosas para } \\
\text { las personas, realizarlas con estas máquinas es más } \\
\text { práctico }\end{array}$ & $\begin{array}{l}\text { Realización de múltiples tareas sobre todo } \\
\text { intrahospitalarias, como la desinfección, que ayudan a que } \\
\text { el tiempo que se ocuparía para realizarlas por seres } \\
\text { humanos se use en otras labores }\end{array}$ \\
\hline Escáner 3D & $\begin{array}{l}\text { Dispositivo que analiza un objeto o un escenario para } \\
\text { reunir datos de su forma, con el fin de construir } \\
\text { modelos digitales tridimensionales con múltiples } \\
\text { aplicaciones }\end{array}$ & $\begin{array}{l}\text { Detección automatizada cuantitativa de virus a alta } \\
\text { velocidad Evaluación de imágenes radiográficas y } \\
\text { tomográficas para diagnóstico preciso de COVID-19 }\end{array}$ \\
\hline $\begin{array}{l}\text { Impresoras } \\
3 \mathrm{D}\end{array}$ & $\begin{array}{l}\text { Máquina que tiene la capacidad de realizar réplicas de } \\
\text { diseños en tercera dimensión, creando piezas o } \\
\text { maquetas volumétricas a partir de un diseño hecho por } \\
\text { un ordenador }\end{array}$ & $\begin{array}{l}\text { Fabricación de mascarillas en un periodo corto de tiempo, } \\
\text { que no tiene el inconveniente de ser contaminantes del } \\
\text { ambiente, como la NanoHack-3D, que es reciclable y } \\
\text { reutilizable }\end{array}$ \\
\hline Biosensores & $\begin{array}{l}\text { Instrumento para la medición de parámetros biológicos } \\
\text { o químicos, suele combinar un componente de } \\
\text { naturaleza biológica y otro fisicoquímico }\end{array}$ & $\begin{array}{l}\text { Detectores en forma de parches para parámetros biológicos, } \\
\text { como síntomas de la enfermedad, temperatura corporal, } \\
\text { glucemia, electrocardiograma, etc. }\end{array}$ \\
\hline
\end{tabular}

COVID-19: enfermedad por coronavirus 2019.

Adaptada de Javaid, et al., $2020^{15}$.

respiratoria y neurología, muchos hospitales que cuentan con la infraestructura necesaria echaron mano de la teleoncología (TO) para atender a los pacientes con cáncer durante la pandemia, en especial para la supervisión de quimioterapia, manejo de síntomas y cuidados paliativos, lo cual disminuyó los riesgos de contagio al personal de salud de los servicios oncológicos y evitó la adquisición de COVID19 hacia los pacientes, dada la alta mortalidad que ha sido reportada en estos. Ejemplos de la aplicación de TO se llevaron a cabo por la Sociedad Europea de Oncología Médica, que transfirió la consulta a medios telefónicos y mediante tecnología web: la renovación de las prescripciones, así como evaluación de 
toxicidad de quimioterapia, adaptación de dosis de fármacos y recomendaciones de cuidados paliativos y de soporte $^{16}$. La experiencia ha demostrado que la TO ha dejado satisfechos tanto a los pacientes como a los proveedores de los servicios y se considera como un método eficiente y costo-efectivo de proporcionar cuidados de alta calidad, lo cual se ha trasladado a la atención durante la pandemia de pacientes con sospecha de COVID-19 mediante evaluación de casos sospechosos por videoconferencias, así como para el seguimiento domiciliario de casos leves. Aunque además de una falta de disponibilidad de la tecnología para implementarla, se agregó que muchos pacientes tenían deficiencias auditivas o visuales 0 desconocían varios aspectos del área tecnológica. Un estudio realizado durante la pandemia mostró un incremento significativo del interés en la población hacia la telesalud en hospitales norteamericanos ( $r: 0.948 ; p<0.001)$ y probablemente aumente la demanda de su uso en los próximos años y no solo de pacientes oncológicos ${ }^{17}$.

Si hace algunos meses, al principio del año 2020, el que seguramente nos dejará una huella imborrable, nos hubieran comentado lo que sucedería en el mundo con una enfermedad ocasionada por un organismo de los más pequeños que existen en este planeta, probablemente la mayoría no lo hubiera creído, sin embargo continuamos viviendo sus consecuencias e impactos, los cuales seguirán hasta que concluya, lo que puede, de acuerdo con la OMS, no ocurrir hasta el año 2022. No todo ha sido negativo, pues para la ciencia y la tecnología han existido rápidos avances superiores a otros años. Hemos presentado muchos de los impactos en estas disciplinas y seguramente se habrán quedado en el tintero muchos más.

\section{Financiamiento}

La presente investigación no ha recibido ayudas específicas provenientes de agencias del sector público, sector comercial o entidades sin ánimo de lucro.

\section{Conflicto de intereses}

El autor declara no tener conflicto de intereses alguno.

\section{Responsabilidades éticas}

Protección de personas y animales. Los autores declaran que para esta investigación no se han realizado experimentos en seres humanos ni en animales.

Confidencialidad de los datos. Los autores declaran que en este artículo no aparecen datos de pacientes.

Derecho a la privacidad y consentimiento informado. Los autores declaran que en este artículo no aparecen datos de pacientes.

\section{Bibliografía}

1. Kupferschmidt K, Cohen J. WHO lauches global megatrial of four most promising coronavirus treatments [Internet]. Science, American Association for the Advancement of Science; 22/03/2020. Disponible en: https:/ www.sciencemag.org/news/2020/03/who-launches-global-megatrial-four-most-promising-coronavirus-treatments\#

2. Thomas J. Lab antibody, anti-viral research aids COVID-19 response [Internet]. Lawrence Livermore National Laboratory; 17/07/2020. Disponible en: https://www.Ilnl.gov/news/lab-antibody-anti-viral-research-aids-covid-19-response

3. EMBL's response to the coronavirus outbreak. EMBL is committed to providing a safe and healthy working environment for our staff and visitors [Internet]. EMBL, 27/04/2020. Disponible en: https//www.embl.org/news/ lab-matters/corona-updates

4. Lourenco S, Tasimi A. No participant left behind: conducting science during COVID-19. Trends Cogn Sci. 2020;24(8):583-4.

5. Introductions to the community: Early-career researchers in the time of COVID-19. Cell Stem Cell. 2020;27(1):13-4.

6. Nowakowska J, Sobocinska J, Lewicki M, Lemańska Ż, Rzymski P. When science goes viral: The research response during the three months of the COVID-19 outbreak. Biomed Pharmacother. 2020;129:110451.

7. Hagerty SL, Williams LM. The impact of COVID-19 on mental health: The interactive roles of brain byotipes and human connection. Brain Behav Immun Health. 2020;5:100078.

8. Ventatesh V. Impacts of COVID-19: a research agenda to support people in their fight. Int J Inf Manage. 2020 Jul 18;102197. doi: 10.1016/j.ijinfomgt.2020.102197. Online ahead of print.

9. Elavarasan RM, Pugazhendhi R. Restructured society and enviroment: A review on potential technological strategies to control the COVID pandemic. Sci Total Environ. 2020;725:138858.

10. Browne $R$. The internet is under huge strain because of the coconavirus. Experts say it can cope-for now [Internet]. CNBC; 27/03/2020. Disponible en: https://www.cnbc.com/2020/03/27/coronavirus-can-the-internet-handle-unprecedented-surge-in-traffic.html

11. Iyengar K, Upadhyaya GK, Vaishya R, Jain V. COVID-19 and applications of smartphone technology in the current pandemic. Diabetes Metab Syndr. 2020;14(5):733-7.

12. Lalmuanawma S, Hussain J, Chhakchhuak L. Applications of machine learningn and artificial intelligence for COVID-19 (SARS-CoV-2) pandemic: a review. Chaos Solitons Fractals. 2020;139:110059.

13. Mohanty S, Harun Ai Rashid M, Mridul M, Mohanty C, Swayamsiddha S. Application of Artificial Intelligence in COVID-19 drug repurposing. Diabetes Metab Syndr. 2020;14(5):1027-31.

14. Najmul AKM, Laato S, Talukder S, Sutinen E. Misinformation sharing and social media fatigue during COVID-19: an affordance and cognitive load perspective. Technol Forecast Soc Change. 2020;159:120201.

15. Javaid M, Haleem A, Vaishya R, Bahl S, Suman R, Vaish A. Industry 4.0 technologies and their applications in fighting COVID-19 pandemic. Diabetes Metab Syndr. 2020;14(4):419-22.

16. Shirke M, Shaikh SA, Harky A. Tele-oncology in the COVID era: The way forward? Trends Cancer. 2020;6:547-49.

17. Hong YR, Lawrence J, Williams D Jr, Mainous A III. Population-level interest and telehealth capacity of US hospitals in response to COVID-19: cross sectional analysis of Google search and National Hospital Survey data. JMIR Public Health Surveill. 2020;6(2):e18961. 